\title{
SENGKETA PEMILIHAN KEPALA DAERAH YANG DIIKUTI OLEH CALON TUNGGAL DI KABUPATEN PATI \\ (Study Kasus Pemilihan Kepala Daerah di Kabupaten Pati Tahun 2017)
}

\author{
Moh. Sofiyan Hadi, Suparnyo dan Subarkah \\ Email : mohsofyan_hadi@gmail.com,suparnyo@umk.ac.id, subarkah_sh@yahoo.com \\ Fakultas Hukum Universitas Muria Kudus
}

\begin{abstract}
ABSTRAK
Pemilihan Umum (Pemilu) merupakan suatu wujud nyata dari demokrasi dan menjadi sarana bagi rakyat dalam menyatakan kedaulatannya terhadap, Negara dan pemerintah. Faktor-faktor yang harus diidentifikasikan karena suatu kelemahan yang terjadi maka prosesnya tidak hanya berhenti pada pemilihan hukum sebagai sarana saja tetapi pengetahuan yang mantap tentang sifat-sifat hukum juga perlu diketahui untuk agar tahu batas-batas di dalam penggunaan hukum sebagai sarana untuk mengubah ataupun mengatur perilaku warga masyarakat. Sengketa pemilihan hasil pemilih (PHP) di Kabupaten Pati tidak memenuhi syarat Pasal 158 ayat (2) UU 10/2016 jundo Pasal 6 ayat (2) PMK 1/2017 sehingga ditolak di Mahkamah Konstitusi. Tim Advokasi Gerakan Masyarakat Pati (GERAM PATI) ketika mengajukan ke Mahkamah Konstitusi juga kadaluwarsa, perselisihannya sebanyak 341.913 suara atau 49,02\%, sedangkan syaratnya seharusnya $0,5 \%$ karena penduduk Kabupaten Pati lebih 1.000.000 penduduk, Tim Advokasi Gerakan Masyarakat Pati (GERAM PATI) bukan peserta pemilihan calon Bupati dan Wakil Bupati Kabupaten Pati tahun 2017, bukan lembaga pemantau pemilihan yang terdaftar dan mendapatkan akreditasi dari KPU.
\end{abstract}

Kata Kunci : Sengketa Pilkada, Calon Tunggal, Gugatan MK, Pati 


\section{PENDAHULUAN}

Pemilihan Umum (Pemilu) merupakan suatu wujud nyata dari demokrasi dan menjadi sarana bagi rakyat dalam menyatakan kedaulatannya terhadap Negara. Kedaulatan rakyat diwujudkan melalui pemilu sebagai wujud hak asasi politik rakyat pemilu maka dapat melaksanakan pergantian pemerintahan secara aman, damai, dan tertib dalam pembangunan nasional. Hal ini sejalan dengan pendapat Haryanto yang menyatakan bahwa:

Pemilihan umum merupakan kesempatan bagi para warga negara untuk memilih pejabatpejabat pemerintah dan memutuskan apakah yang mereka inginkan untuk dikerjakan oleh pemerintah dan dalam membuat keputusan itu para warga negara menentukan apakah yang sebenarnya yang mereka inginkan untuk dimiliki. ${ }^{12}$

Pilkada dilakukan secara serentak di Kabupaten Pati pada tanggal 15 Februari 2017 memiliki berbagai macam fenomena yang menarik. Pilkada Kabupaten Pati merupakan salah satu yang menarik karena satusatunya Pilkada yang hanya diikuti oleh satu calon Bupati dan Wakil Bupati. Sejak dibuka pendaftaran calon bupati pada 21-23 September 2016 hanya satu pasangan calon bupati dan wakil bupati. KPU Pati menunggu hingga batas waktu akhir atau pukul 24.00 pada 23 September 2016, KPU Pati menetapkan pendaftaran perpanjangan

12 Soedarto, "Hukum Pidana dan Perkembangan Masyarakat dalam Kajian Hukum Pidana", Sinar Baru, Bandung, 1983 Hal. 74 pasangan calon dari 28-30 September 2016. Pasangan ini didukung gabungan partai politik; PDIP, Gerindra, PKB, Demokrat, Golkar, Hanura, PKS, dan PPP. Total dukungan 46 kursi dari 50 kursi di DPRD Pati.

Pasangan Haryanto dan Saiful Arifin akhirnya ditetapkan oleh KPU Pati pada 24 Oktober 2016 sebagai Calon Bupati dan Wakil Bupati Pati. ${ }^{13}$ Pasangan ini ditetapkan menjadi calon tunggal. Keberadaan calon ini didukung putusan MK Nomor 100/PUU-XIII/2015. Calon tunggal diperbolehkan maju di Pilkada Serentak 2017. Lawannya kotak kosong. Melihat pertimbangan diatas itu di hasil sidang gugatan Relawan Kotak Kosong ditolak oleh majelis hakim MK. Gugatan itu dinilai tidak memenuhi tenggat waktu pengajuan gugatan. MK juga menolak gugatan relawan kotak kosong karena dinilai tidak memiliki kedudukan hukum kuat sebagai pemohon yang mengajukan gugatan perselisihan hasil pemilu (PHP) Pilkada Pati.

Pemohon mengajukan materi gugatan pada Selasa, 28 Februari 2017 lalu. Eksepsi termohon yang lain terkait ambang batas 0,5 perolehan suara dan legal standing pemohon PHP secara otomatis diterima. ${ }^{14}$ Adanya putusan MK itu membuat pasangan HaryantoSaiful Arifin ditetapkan bupati dan wakil bupati Pati Terpilih. KPU Pati menyampaikan hasil pilkada Pati 2017 itu kepada DPRD Pati.

Dari latar belakang di atas maka penulis akan melakukan pembahasan dengan judul Sengketa Pemilihan Kepala Daerah yang Diikuti oleh Calon

\footnotetext{
13"Radar Kudus", 25 Oktober 2016, hlm. 1

14"Radar Kudus", 5 April 2017, hlm 1
} 
Tunggal di Kabupaten Pati (Study Kasus Pemilihan Kepala Daerah di Kabupaten Pati Tahun 20017), yang dirumuskan dalam beberapa permasalahan sebagai berikut :

1. Apa saja faktor-faktor yang melatarbelakangi terjadinya calon tunggal dalam Pilkada ?

2. Mengapa relawan kotak kosong mengajukan suatu gugatan Perselisihan Hasil Pemilu (PHP) Pilkada Pati di MK?

3. Bagaimana putusan Mahkamah Konstitusi tentang gugatan Perselisihan Hasil Pemilu (PHP) di Pati?

\section{METODE PENELITIAN}

Penelitian ini mendasarkan pada penelitian hukum yang dilakukan dengan pendekatan non-doktrinal yang kualitatif. Hal ini disebabkan di dalam penelitian, hukum tidak hanya dikonsepkan sebagi keseluruhan asasasas dan kaidah yang mengatur kehidupan manusia dalam masyarakat, melainkan juga lembaga-lembaga dan proses-proses yang mewujudkan berlakunya kaidah-kaidah itu dalam masyarakat.

Penelitian akan dilakukan di Kabupaten Pati, Jawa Tengah. Penentuan lokasi ini dilakukan secara purposive, yang didasarkan pada pertimbangan-pertimbangan yaitu karena daerah ini merupakan salah satu daerah yang mempunyai masalah tentang keberlangsungan kotak kosong pada pilkada, untuk mengetahui hasil gugatan paska Pilkada Pati, serta untuk mengetahui legalitas atau kedudukan hukum tentang status kotak kosong Pilkada Pati.

Spesifikasi penelitian ini bersifat deskriptif, yaitu menggambarkan secara jelas dan memahami tentang berbagai hal yang terkait dengan objek yang diteliti, yaitu pilkada calon tunggal, keberlangsungan kotak kosong pasca hasil gugatan pilkada, serta peran dan strategi dari kelompok kotak kosong dalam pilkada gugatan MK.

Penelitian ini membutuhkan dua jenis data yang berasal dari dua sumber yang berbeda, yaitu data primer dan data sekunder. Data primer diperoleh dengan cara wawancara dan observasi, sedangkan sekunder dengan melakukan dengan studi kepustakaan.

\section{HASIL PENELITIAN DAN PEMBAHASAN}

\section{Sengketa Pemilihan Kepala \\ Daerah yang Diikuti oleh Calon Tunggal di Kabupaten Pati}

Partai politik atau gabungan partai politik dapat mendaftarkan atau mengusung bakal pasangan calon Bupati dan wakil Bupati minimal memiliki 20\% dari jumlah DPRD Kabupaten Pati hasil Pemilu 2014 yaitu 10 kursi atau paling sedikit $25 \%$ dari akumulasi perolehan suara sah pemilu 2014 yaitu minimal 179.449 (seratus tujuh puluh sembilan ribu empat ratus empat puluh sembilan) suara sah.. Adapun pasangan perseorangan dapat memenuhi persyaaratan minimal $6,5 \%$ (enam koma lima) dari jumlah pemilih pemilu terakhir pemilu Presiden dan Wakil Presiden tahun 2014 di Kabupaten Pati, yaitu sebanyak 67.015 (enam puluh tujuh ribu lima belas) dan penyebaran pendukung minimal 11 (sebelas) Kecamatan.

Pada tanggal 22 September 2016 pukul 10.00 WIB, gabungan dari 8 (delapan) partai politik yaitu Partai Demokrat, PDIP, Gerindra, Hanura, 
PKB, PPP, PKS dan Golkar, mendaftarkan H. Hariyanto, M.Si. sebagai bakal calon Bupati dan $\mathrm{H}$. Saiful Arifin sebagai bakal calon wakil Bupati, semuanya diterima oleh Ketua dan seluruh angggota KPU Kabupaten Pati.

Jumlah Daftar Pemilih Tetap (DPT) yang ditetapkan oleh Komisi Pemilihan Umum (KPU) Kabupaten Pati pada tanggal 6 Desember 2016 Nomor 95/BA/KPU-Kab.Pati/XII/ 2016 tentang rapat pleno terbuka reapitulasi pemilih sementara hasil perbaikan (DPSHP) dan penetapan daftar pemilih tetap (DPT) Pemilihan Bupati dan Wakil Bupati Kabupaten Pati tahun 2017 adalah 1.034.256 pemilih.

\section{Tabel 2.2}

Rekapitulasi DPT Per Kecamatan

\begin{tabular}{|c|c|c|c|c|c|c|}
\hline \multirow[t]{2}{*}{ No } & \multirow{2}{*}{$\begin{array}{c}\mathrm{Kec} \\
\text { amat } \\
\text { an }\end{array}$} & \multirow{2}{*}{$\begin{array}{l}\text { D } \\
\text { es } \\
\text { a }\end{array}$} & \multirow{2}{*}{$\begin{array}{c}\mathrm{TP} \\
\mathrm{S}\end{array}$} & \multicolumn{3}{|c|}{ Jumlah Pemilih } \\
\hline & & & & $\mathrm{L}$ & $\mathrm{P}$ & $\mathrm{L}+\mathrm{P}$ \\
\hline 1 & $\begin{array}{l}\text { Bata } \\
\text { ngan }\end{array}$ & 18 & 77 & $\begin{array}{l}16 . \\
631\end{array}$ & $\begin{array}{l}17 . \\
294\end{array}$ & $\begin{array}{l}33.9 \\
25\end{array}$ \\
\hline 2 & $\begin{array}{l}\text { Clu } \\
\text { wak }\end{array}$ & 13 & 87 & $\begin{array}{l}18 . \\
641\end{array}$ & $\begin{array}{l}19 . \\
392\end{array}$ & $\begin{array}{l}38.0 \\
33\end{array}$ \\
\hline 3 & $\begin{array}{l}\text { Duk } \\
\text { uh } \\
\text { sekti }\end{array}$ & 12 & $\begin{array}{l}10 \\
5\end{array}$ & $\begin{array}{l}23 . \\
721\end{array}$ & $\begin{array}{l}23 . \\
944\end{array}$ & $\begin{array}{l}47.6 \\
65\end{array}$ \\
\hline 4 & $\begin{array}{l}\text { Gab } \\
\text { us }\end{array}$ & 24 & $\begin{array}{l}11 \\
3\end{array}$ & $\begin{array}{l}2.9 \\
68\end{array}$ & $\begin{array}{l}26 . \\
004\end{array}$ & $\begin{array}{l}50.9 \\
72\end{array}$ \\
\hline 5 & $\begin{array}{l}\text { Gem } \\
\text { bong }\end{array}$ & 11 & 78 & $\begin{array}{l}18 . \\
205\end{array}$ & $\begin{array}{l}18 . \\
961\end{array}$ & $\begin{array}{l}37.1 \\
66\end{array}$ \\
\hline 6 & $\begin{array}{l}\text { Gun } \\
\text { ung } \\
\text { wun } \\
\text { gkal }\end{array}$ & 15 & 72 & $\begin{array}{l}14 . \\
718\end{array}$ & $\begin{array}{l}15 . \\
504\end{array}$ & $\begin{array}{l}30.2 \\
22\end{array}$ \\
\hline 7 & $\begin{array}{l}\text { Jake } \\
\mathrm{n}\end{array}$ & 21 & 89 & $\begin{array}{l}18 . \\
281 \\
\end{array}$ & $\begin{array}{l}19 . \\
354\end{array}$ & $\begin{array}{l}37.6 \\
35 \\
\end{array}$ \\
\hline 8 & $\begin{array}{l}\text { Jake } \\
\text { nan }\end{array}$ & 23 & 88 & $\begin{array}{l}19 . \\
065\end{array}$ & $\begin{array}{l}20 . \\
246\end{array}$ & $\begin{array}{l}39.7 \\
60\end{array}$ \\
\hline 9 & Juw & 29 & 15 & 34. & 35. & 70.7 \\
\hline
\end{tabular}

\begin{tabular}{|c|c|c|c|c|c|c|}
\hline & ana & & 7 & 922 & 838 & 60 \\
\hline 10 & $\begin{array}{l}\text { Kay } \\
\text { en }\end{array}$ & 17 & $\begin{array}{l}11 \\
7\end{array}$ & $\begin{array}{l}31 . \\
149\end{array}$ & $\begin{array}{l}31 . \\
513\end{array}$ & $\begin{array}{l}62.6 \\
62\end{array}$ \\
\hline 11 & $\begin{array}{l}\text { Mar } \\
\text { gore } \\
\text { jo }\end{array}$ & 18 & 98 & $\begin{array}{l}22 . \\
315\end{array}$ & $\begin{array}{l}23 . \\
851\end{array}$ & $\begin{array}{l}46.1 \\
66\end{array}$ \\
\hline 12 & $\begin{array}{l}\text { Mar } \\
\text { goyo } \\
\text { so }\end{array}$ & 22 & $\begin{array}{l}13 \\
1\end{array}$ & $\begin{array}{l}28 . \\
425\end{array}$ & $\begin{array}{l}28 . \\
496\end{array}$ & $\begin{array}{l}56.9 \\
21\end{array}$ \\
\hline 13 & Pati & 29 & $\begin{array}{l}19 \\
0\end{array}$ & $\begin{array}{l}39 . \\
743\end{array}$ & $\begin{array}{l}43 . \\
222\end{array}$ & $\begin{array}{l}82.9 \\
65\end{array}$ \\
\hline 14 & $\begin{array}{l}\text { Punc } \\
\text { ak } \\
\text { wan } \\
\text { gi }\end{array}$ & 20 & 99 & $\begin{array}{l}19 . \\
501\end{array}$ & $\begin{array}{l}20 . \\
025\end{array}$ & $\begin{array}{l}39.5 \\
26\end{array}$ \\
\hline 15 & $\begin{array}{l}\text { Suk } \\
\text { olilo }\end{array}$ & 16 & $\begin{array}{l}15 \\
3\end{array}$ & $\begin{array}{l}34 . \\
678\end{array}$ & $\begin{array}{l}35 . \\
425\end{array}$ & $\begin{array}{l}70.1 \\
03\end{array}$ \\
\hline 16 & $\begin{array}{l}\text { Tam } \\
\text { bakr } \\
\text { omo }\end{array}$ & 18 & $\begin{array}{l}10 \\
2\end{array}$ & $\begin{array}{l}22 . \\
106\end{array}$ & $\begin{array}{l}22 . \\
699\end{array}$ & $\begin{array}{l}44.8 \\
05\end{array}$ \\
\hline 17 & $\begin{array}{l}\text { Tay } \\
\mathrm{u}\end{array}$ & 21 & $\begin{array}{l}11 \\
9\end{array}$ & $\begin{array}{l}26 . \\
906\end{array}$ & $\begin{array}{l}27 . \\
615\end{array}$ & $\begin{array}{l}54.5 \\
21\end{array}$ \\
\hline 18 & $\begin{array}{l}\text { Tlo } \\
\text { wun } \\
\text { gu }\end{array}$ & 15 & 82 & $\begin{array}{l}21 . \\
002\end{array}$ & $\begin{array}{l}21 . \\
426\end{array}$ & $\begin{array}{l}42.4 \\
28\end{array}$ \\
\hline 19 & $\begin{array}{l}\text { Tran } \\
\text { gkil }\end{array}$ & 16 & $\begin{array}{l}10 \\
6\end{array}$ & $\begin{array}{l}23 . \\
588\end{array}$ & $\begin{array}{l}24 . \\
334\end{array}$ & $\begin{array}{l}47.9 \\
22\end{array}$ \\
\hline 20 & $\begin{array}{l}\text { Wed } \\
\text { ari } \\
\text { jaks } \\
\text { a }\end{array}$ & 18 & $\begin{array}{l}10 \\
9\end{array}$ & $\begin{array}{l}24 . \\
035\end{array}$ & $\begin{array}{l}24 . \\
526\end{array}$ & $\begin{array}{l}48.5 \\
61\end{array}$ \\
\hline 21 & $\begin{array}{l}\text { Win } \\
\text { ong }\end{array}$ & 30 & $\begin{array}{l}12 \\
3\end{array}$ & $\begin{array}{l}25 . \\
419\end{array}$ & $\begin{array}{l}26 . \\
568\end{array}$ & $\begin{array}{l}51.9 \\
87\end{array}$ \\
\hline & $\begin{array}{l}\text { Tota } \\
1\end{array}$ & $\begin{array}{l}40 \\
6\end{array}$ & $\begin{array}{l}2 . \\
29 \\
5\end{array}$ & $\begin{array}{l}508 \\
.01 \\
9\end{array}$ & $\begin{array}{l}526 \\
.23 \\
7\end{array}$ & $\begin{array}{l}1.03 \\
4.25 \\
6\end{array}$ \\
\hline
\end{tabular}

Pada tanggal 23 Februari 2017 Komisi Pemilihan Umum (KPU) Kabupaten Pati mengeluarkan surat keputusan penetapan hasil pilihan dan rekapitulasi pemilihan Bupati dan Wakil Bupati tahun 2017 Nomor 16/Kpts/KPUKab.Q12.329311/2017 
tentang Penetapan Rekapitulasi Hasil Pemilihan Bupati dan Wakil Bupati Tahun 2017.

Tuntutannya kepada Mahkamah Konstitusi adalah sebagai berikut:

1. Mengabulkan permohonan para pemohon untuk seluruhnya.

2. Membatalkan Keputusan Komisi Pemilihan/Komisi Independen Pemilihan Kabupaten Pati Nomor 16/Kpts/KPU-Kab.012.329311/ 2017 tentang Penetapan Rekapitulasi Hasil Pemilihan Bupati dan Wakil Bupati Tahun 2017, tanggal 23 Februari 2017, pukul 15.05 WIB.

3. Menetapkan Perolehan Suara Hasil Pemilihan Calon Bupati dan Wakil Bupati Pati Tahun 2017 yang benar menurut Pemohon sebagal berikut:

1) Pasangan Calon Nomor Urut 1 H. Haryanto, S.H., M.M., M.Si. dan H. Saiful Arifin 300.000 (tiga ratus ribu)

2) Kolom Kosong 700.000 (tujuh ratus ribu)

Total Pemilih atau pengguna hak suara dari 1.030.676 jiwa pengguna hak pillh berdasarkan angka KPU Kabupaten Pati.

4. Memerintahkan kepada KPU Kabupaten Pati untuk melaksanakan putusan ini atau apabila Mahkamah Konstitusi berpendapat lain, mohon putusan yang seadil-adilnya.

\section{Peran dan Strategi Kotak Kosong dalam Pilkada}

Strategi pertama, kelompok kepentingan dapat menggunakan strategi lobi disesuaikan dengan konteks kepentingan masing-masing. Strategi lobi yang dilakukan oleh AKDP adalah dengan melobi pihak pihak terkait penyelenggaraan Pilkada seperti KPU, Panwas, dan Kepolisian, bahwa mereka berhak untuk menyelenggarakan kegiatan sosialisasi dan kampanye pilihan "kotak kosong".

Strategi kedua dari kelompok kepentingan adalah dengan membuka akses kepada pembuat kebijakan dan memobilisasi sumber daya yang mereka miliki. Strategi ketiga adalah kelompok kepentingan dapat memobilisasi pemilih agar dapat mempengaruhi hasil pemilu. AKDP berusaha menggalang pilihan dan mobilisasi suara pemilih agar memilih "kotak kosong" dengan menggunakan medium Facebook Group. Ada dua Facebook Group yang aktif atau online yaitu "Relawan Kotak Pati" dan "Relawan Kotak Kosong Pati Bumi Mina".

Strategi berikutnya adalah dengan mengontrol informasi kepada pemilih pada umumnya dengan membentuk opini publik dengan membentuk kerangka (frame) karena mereka memiliki sumber daya yang terbatas. Tujuan dipasangnya spanduk di Posko yang terletak di pinggir jalan itu adalah agar mendapat perhatian baik dari masyarakat sekitar dan yang melintasi Posko tersebut atau menarik perhatian media massa lokal. Tujuannya adalah agar mereka dapat memastikan bahwa tidak ada kecurangan yang terjadi. Strategi kelima dari AKDP adalah dengan melakukan advokasi dengan cara memperbesar dan memperluas koalisi atau 50 Peran dan Strategi Kelompok "Kotak Kosong" dalam Pilkada Calon Tunggal Kabupaten Pati Tahun 2017.

Fenomena munculnya kasus calon tunggal dalam pemilukada adalah bahwa para pengurus partai politik 
sebagian besar lebih banyak mengajukan para bakal calon kepala daerahnya atas dasar pertimbangan untung rugi finansial dan menang kalah politik, daripada keberanian untuk maju terus pantang mundur, menang atau kalah. Calon tunggal bila tidak hati-hati dapat membahayakan demokrasi, meskipun adanya calon tunggal tersebut karena seseorang didukung dan dicintai oleh mayoritas masyarakat daerah setempat. Fenomena calon tunggal ini bila dibiarkan berlarut-larut tidak mustahil akan merembet pada pemilihan presiden. Hal tersebut akan membuat ketiadaan demokrasi di suatu negara. Kondisi tersebut menandakan bahwa seseorang telah menguasai partai politik. $^{15}$

\section{Kesimpulan}

Pemilihan Bupati dan Wakil Bupati Pati berjalan sesuai dengan Undang-Undang dan tidak ada hambatan sampai pemungutan hasil suara dan hanya diikuti oleh calon tungggal yaitu H. Hariyanto, S.H., M.Si. dan H. Saiful Arifin melawan kota kosong. Komisi Pemilihan Umum sudah memberikan perpanjangan waktu pendaftaran aan tetapi, tetap satu calon yang mendaftaran sebagai calon Bupati dan Wakil Bupati di Kabupaten Pati.

Adapun daftar pemilih tetap (DPT) Pemilihan Bupati dan Wakil Bupati Kabupaten Pati tahun 2017 adalah 1.034.256 pemilih, terdiri dari 406 desa dan 2.295 TPS. Pasangan calon H. Hariyanto, M. S.i dan Saiful Arifin memperoleh suara 519.675 Kolom Kosong memperoleh 177.762

\footnotetext{
${ }^{15}$ Aryojati Ardipandanto, "Calon Tunggal dalam Pilkada Serentak 2015", Info Singkat Kajian Singkat terhadap Isu Aktual dan Strategis, Vol. VII No. 15 Agustus 2015, hlm. 19-20
}

suara perselisihannya sebanyak 341.913 suara atau 49,02\%, Tim Advokasi Gerakan Masyarakat Pati (GERAM PATI) mengajukan permohonannya ke Mahkamah Konstitusi sebagai berikut:

1. Membatalkan hasil pilihan pemungutan suara yang ditetapkan oleh KPU Kabupaten Pati.

2. Menuntut kecurangan-kecurangan yang ada di lapangan.

Peran AKDP juga memfokuskan pada isu tertentu dan menguntungkan anggota mereka sendiri, meningkatkan level atau tingkat yang ingin mereka capai, dan menggunakan power atau kekuasaan yang mereka miliki. Selain itu, AKDP juga memiliki lima strategi. Strategi-strategi itu adalah menggunakan strategi lobi, membuka akses kepada pembuat kebijakan dan memobilisasi sumber daya yang mereka miliki, memobilisasi pemilih, mengontrol informasi kepada pemilih pada umumnya, dan melakukan advokasi.

\section{Saran}

Berdasarkan uraian di atas, penulis dapat memberikan saran:

a. Partai politik harus menjalin kerjasama yang baik dengan KPU Kabupaten Pati agar Pemilihan Legislatif dan Pemilihan Umum Kepala Daerah yang diselenggarakan berjalan dengan baik dan tidak menciptakan peristiwa-peristiwa yang dapat menghambat jalannya pesta rakyat tersebut.

b. Partai politik seharusnya mampu mengusung para kadernya yang berkompeten pada Pemilihan Umum Kepala Daerah yang diselenggarakan. Partai politik 
harus mempersiapkan para kadernya yang berkompetensi tersebut jauh-jauh hari sebelum Pemilihan Umum Kepala Daerah tersebut diselenggarakan.

c. Partai politik sebagai alat rekrutmen politik dan masyarakat memberikan kepercayaan untuk menyeleksi seseorang yang mempunyai kompeten dan kredibilitas seharusnya mampu tidak bersikap pragmatis. Proses pembentukan koalisi oleh partaipartai untuk mengusung seseorang seharusnya juga tidak melakukan "pemborongan" partai sehingga membuat gabungan partai politik peserta Pemilihan Umum Kepala Daerah lainnya tidak dapat mendaftarkan calon.

\section{DAFTAR PUSTAKA}

Ardipandanto, Aryojati. 2015. "Calon Tunggal dalam Pilkada Serentak 2015”. Info Singkat Kajian Singkat terhadap Isu Aktual dan Strategis, Vol. VII No. 15

C.S.T. Kansil, "Evaluasi Pilkada 2017 Pilkada Transisi Gelombang kedua Menuju Pilkada Serentak Nasional", edisi 10, Jakarta.

Haris, Syamsudin. 2005. "Pemilu Langsung di Tengah Oligarki Partai". Jakarta: PT Gramedia Pustaka Utama

Jurnal Sumatera. (2016, Desember 23). Kampanye Kotak Kosong di Pati Mulai Muncul.

Neke, Defriatno, (2017, Februari 6). Sekelompok Warga Kampanyekan Kotak Kosong untuk Pilkada Buton.
Radar Kudus", 28 Oktober 2016.

Radar Kudus", 25 Oktober 2016.

Radar Kudus", 5 April 2017.

Roziki, Yayan Isro, (2017, Februari 23). Ini Hasil Rekapitulasi Suara Pilkada Pati, Kotak Kosong Dipilih Lebih Dari 170 Ribu Warga. Tribun Jateng.

Safuan, Akhmad, (2016, Desember 26). Pilkada Pati, Kotak Kosong Mulai Kampanye.

Soedarto, "Hukum Pidana dan Perkembangan Masyarakat dalam Kajian Hukum Pidana", Sinar Baru, Bandung, 1983.

Sumber KPU 2017

Sudikno Mertokusumo, "Hukum Acara Perdata Indonesia”, Yogyakarta, 1998. 